http://jmscr.igmpublication.org/home/

ISSN (e)-2347-176x ISSN (p) 2455-0450

crossref DOI: https://dx.doi.org/10.18535/jmscr/v7i8.120

Journal Of Medical Science And Clinical Research

\title{
Depression and its Association with Quality of Life in Female Patients at Different Hormonal Phases of Life - A Cross Sectional Study in Western U.P.
}

\author{
Authors \\ Dr Sujit Kumar*, Dr Sandeep Choudhary, Dr Supriya Agarwal \\ Department of Psychiatry, NSCB Subharti Medical College, Meerut, U.P. \\ *Corresponding Author \\ Dr Sujit Kumar \\ Department of Psychiatry, NSCB Subharti Medical College, Meerut, U.P., India
}

\begin{abstract}
Gender is undoubtedly one of the major determinants of mental health. One school of thought believes that hormonal influences related to the reproductive cycle of women may play a role increased/differential vulnerability to mental problems. Unipolar Depression, which is predicted to be the second leading cause of global disability burden by 2020, is twice as common in women. Moreover, onset of menarche, maternity, and childbirth per se are stressful events in the life of a female. The purpose of this study was to analyze depression in female patients at different hormonal phases (5 phases, as predefined for this study) and its association with the quality of life in these patients. This cross section observational study involved 60 female patients in the department of psychiatry at a tertiary care teaching hospital in western U.P. Data was collected using self structured Socio-demographic and Clinical data sheets. Hamilton Rating Scale for Depression (HAM-D) and WHO Quality of Life (WHO Qol-BREF) were used as psychometric tools. The test values of continuous variables were expressed as mean $\pm S D$ (standard deviation). The Pearson product-moment correlation was used to determine the strength and direction of a linear relationship. Depression was found in all the hormonal phases with highest (35\%) in late perimenopausal and Severe Depression was found to be highest (60\%) in early perimenopausal group. All the cases of Post Partum Depression were of Moderate type. Pregnant patients presented in all Mild, Moderate and Severe Depressive Episodes. A significant $(P<0.001)$ inverse correlation was found between HAM-D scores and the overall quality of life (total WHOQOL-BREF Score). Pearson's correlation coefficient, $r=-0.596$. Depression scores also correlated significantly with all four domains of WHO quality of life. Depression has shown to significantly influence the quality of life in these subjects.

Keywords: Women, Depression, Hormonal Phases.
\end{abstract}

\section{Introduction}

Women, who constitute about half the World's population, are now the centre of concern as far as health; especially mental health is concerned even in a developing country like India. The problems faced by the female gender associated with their social, physiological and psychological attributes, have led to an increased incidence of Common Mental Disorders (CMD's) like Depression, Anxiety Disorders and Psychosomatic Symptoms $^{(1)}$. Unipolar Depression, which is predicted to be the second leading cause of global 
disability burden by 2020, is twice as common in women. Onset of menarche is believed to represent an important psychosocial and/or biological transition point for the female rise in depression $^{(2)}$, with studies reporting higher levels of depressive symptoms in girls who have experienced menarche compared with those who have not $^{(3)}$, It has also been suggested that the timing of menarche relative to one's peers may be a critical factor for the emergence of depressive symptoms $^{(4)}$, with studies reporting that earlier timing of menarche is associated with increased depressive symptoms ${ }^{(5)}$ and depression ${ }^{(6)}$. Postpartum Depression is seen $11 \%$ in women, which increases to $26 \%$ if only adolescent mothers are considered ${ }^{(7)}$. Estrogens can influence neural activity in the hypothalamus and limbic system directly through modulation of neuronal excitability and have complex multiphasic effects on dopamine receptor sensitivity. The association of estrogens and progesterone with serotonin is hypothetically relevant to mood changes in premenstrual and postpartum mood disturbances $^{(8)}$. Perimenopause is defined by the WHO as the 2-8 years preceding menopause and the 1-year period after final menses, resulting from the loss of follicular activity ${ }^{(9)}$. During this period, production of the estrogen and progesterone becomes more irregular, with wide and unpredictable fluctuations in their levels; the levels of follicle-stimulating hormone increase until months after the last menstrual period leading to diminishing fertility and irregularity of menses ${ }^{(10)}$. Currently, it seems that vulnerability of major depression in midlife women appears to be a myth, but the data accumulating suggest that the menopause transition is a time of increased risk for potentially impairing, depressive symptoms. Both clinical and community-based studies suggest that as compared to premenopausal women, depressive symptoms are more frequently reported in perimenopausal women ${ }^{(11)}$. These women either remain untreated or use unproven alternatives $^{(12)}$.
In this new era of medical science, especially in developed countries, there has been a shift in mental health service policy from an emphasis on treatment focused on reducing symptoms, based on a narrow notion of pathology and illness, to a more holistic approach which takes into consideration well-being, recovery, social functioning, and quality of life ${ }^{(13)}$. An approach where more people attending mental health services recover and have a good quality of life is necessary in our health system.

Due to the worldwide socio-cultural milieu and predominantly patriarchal dominance, being women is a challenge and that challenge with the superimposed mental illness, if any, would act like a "double-edged sword" especially in a country like India. The majority of mental health studies in India are conducted in the progressive states of Goa and Kerala, which have high levels of female empowerment and education, important predictors of mental health ${ }^{(14)}$. This study has analysed the psychiatric morbidities in relation to various hormonal phases amongst women living in and around Meerut, a district in Western Uttar Pradesh and provides an insight into a problem which requires serious intervention. Not many such studies have been done in this backdrop and due to paucity of enough scientific information; we planned to take up this current project.

\section{Materials and Methods}

Study group consisted of 60 female patients amongst outpatients and inpatients of department of psychiatry at a tertiary hospital in Western Uttar Pradesh. It was an observational crosssectional study using consecutive sampling. Till the required sample size of 60 was attained, all new female cases, attending the Psychiatry OPD, after fulfilment of inclusion and exclusion criteria, were taken for the purpose of this study and were evaluated in details. Their clinical diagnoses of Depression were confirmed by a consultant in accordance with ICD 10. Consent was obtained from the participants in the language they understood (Hindi). The patients were evaluated 
using Hamilton Rating Scale for Depression (HAM-D) and all the patients will be assessed for their quality of life using WHO Quality of Life Brief Questionnaire (WHOQOL-BREF). Subsequently the patients were divided into hormonal phases as predefined for purpose of the study. The Hormonal Phases predefined in our study were: Phase 1 - Females of reproductive age group who had attained Menarche and were not Pregnant, Phase 2 - Pregnant patients presenting during antenatal period $\left(1^{\text {st }}, 2^{\text {nd }}\right.$ or $3^{\text {rd }}$ trimester $)$, Phase 3 - Patients who were Postpartum including those in Lactation period, Phase 4 Perimenopausal (Age 45 - 55 Years) where Perimenopause is defined by the WHO as the 2-8 years preceding menopause and the 1-year period after final menses, resulting from the loss of follicular activity [4 A - Early Perimenopausal (Patients having variable cycle length during last period i.e. $>7$ days different from normal menstrual cycle length, which is $21-35$ days) and 4 B - Late Perimenopausal ( $\geq 2$ skipped cycles and an interval of amenorrhea $\geq 60$ days)]. Information so gained and data so collected were subjected to suitable statistical analysis (mean, p-value, Pearson's correlation analysis) and conclusions were drawn using software IBM SPSS Statistics Version 25 (SPSS v25).

\section{Results}

Among 60 cases of depression, 21 patients were from Phase - 4B followed by 17 from Phase $-1,9$ from Phase $-3,8$ from Phase -2 and 5 from Phase $-4 \mathrm{~A}$ in decreasing order of number. Table 1 shows distribution of the data as per number of cases of different types of depression present among the depressive patients in each Pre-defined Hormonal Phases. In Phase - 1, out of 17 patients who had depression mainly presented in Moderate Depressive Episode (76.47\%) and rest in Mild Depressive Episode (23.53\%) but no cases were diagnosed with severe depression in this phase. In Phase - 2, out of 8 patients suffering from depression, 1 had mild, 6 had moderate and 1 had severe depressive episode. Phase - 3 which consisted of patients (9) in postpartum and lactation phase, were all diagnosed to be suffering with moderate depressive episode based on HAMD scores. In Phase $-4 A$, there were 5 patients, 2 of which were diagnosed to have moderate and 3 were diagnosed as cases of severe depressive episode. Finally, in Phase -4B, we had 21 patients out of which $61.9 \%$ had moderate and $38.1 \%$ were diagnosed with severe depressive episode. Figure 1 and Table 2 shows distribution of Hamilton Rating Scale for Depression (HAM-D) scores for 60 patients suffering with depressive disorder. The Mean HAM-D was 16.21 and SD was 2.5 for the sample with Range 10-23. Figure 2 and Table 3 shows Pearson's Correlation Analysis that was done between scores obtained for depression on HAM-D scale and WHOQOL-BREF scores for quality of life. A significant $(\mathrm{P}<0.001)$ inverse correlation was found between HAM-D scores and the overall quality of life (total WHOQOLBREF Score). Pearson's correlation coefficient, $r=$ -0.596. Depression scores also correlated significantly with all four domains of WHO quality of life.

Table 1: Distribution of the data as per number of cases of different types of depression present among the depressive patients in each Pre-defined Hormonal Phases

\begin{tabular}{|c|c|c|}
\hline Phase - 1 & $\begin{array}{ll}\text { Frequency } & \mathrm{N}=17\end{array}$ & $\%$ \\
\hline Mild Depression & 4 & 23.53 \\
\hline Moderate Depression & 13 & 76.47 \\
\hline Severe Depression & 0 & 0 \\
\hline Total & 17 & 100 \\
\hline Phase - 2 & Frequency & $\%$ \\
\hline Mild Depression & 1 & 12.5 \\
\hline Moderate Depression & 6 & 75 \\
\hline Severe Depression & 1 & 12.5 \\
\hline Total & 8 & 100 \\
\hline
\end{tabular}




\begin{tabular}{|c|c|c|c|}
\hline Phase - 3 & Frequency & $N=9$ & $\%$ \\
\hline Mild Depression & \multicolumn{2}{|l|}{ 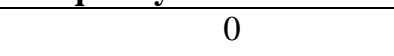 } & 0 \\
\hline Moderate Depression & \multicolumn{2}{|c|}{9} & 100 \\
\hline Severe Depression & \multicolumn{2}{|c|}{0} & 0 \\
\hline Total & \multicolumn{2}{|c|}{9} & 100 \\
\hline Phase-4A & Frequency & $N=5$ & $\%$ \\
\hline Mild Depression & \multicolumn{2}{|l|}{ 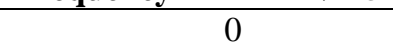 } & 0 \\
\hline Moderate Depression & \multicolumn{2}{|c|}{2} & 40 \\
\hline Severe Depression & \multicolumn{2}{|c|}{3} & 60 \\
\hline Total & \multicolumn{2}{|c|}{5} & 100 \\
\hline Phase - 4B & Frequency & $N=21$ & $\%$ \\
\hline Mild Depression & \multicolumn{2}{|c|}{0} & 0 \\
\hline Moderate Depression & \multicolumn{2}{|c|}{13} & 61.90 \\
\hline Severe Depression & \multicolumn{2}{|c|}{8} & 38.10 \\
\hline Total & \multicolumn{2}{|c|}{21} & 100 \\
\hline
\end{tabular}

Figure 1: Distribution of the data as per Hamilton Rating Scale for Depression (HAM-D) Scores

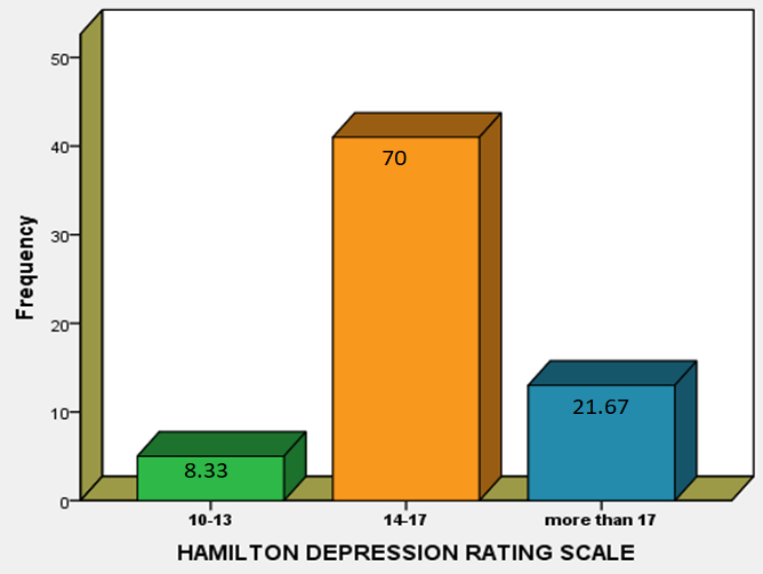

Table 2: Distribution of the data as per Hamilton Rating Scale for Depression (HAM-D) Scores

\begin{tabular}{|c|c|c|}
\hline HAM-D SCORES & Frequency & $\%$ \\
\hline 10-13 (mild) & 5 & 8.33 \\
\hline 14-17 (mild - mod.) more than & 42 & 70 \\
\hline 17 (mod. - severe) & 13 & 21.67 \\
\hline Total & 60 & 100 \\
\hline
\end{tabular}

Figure 2: Pearson's Correlation Analysis of HAM-D versus WHOQOL Scores

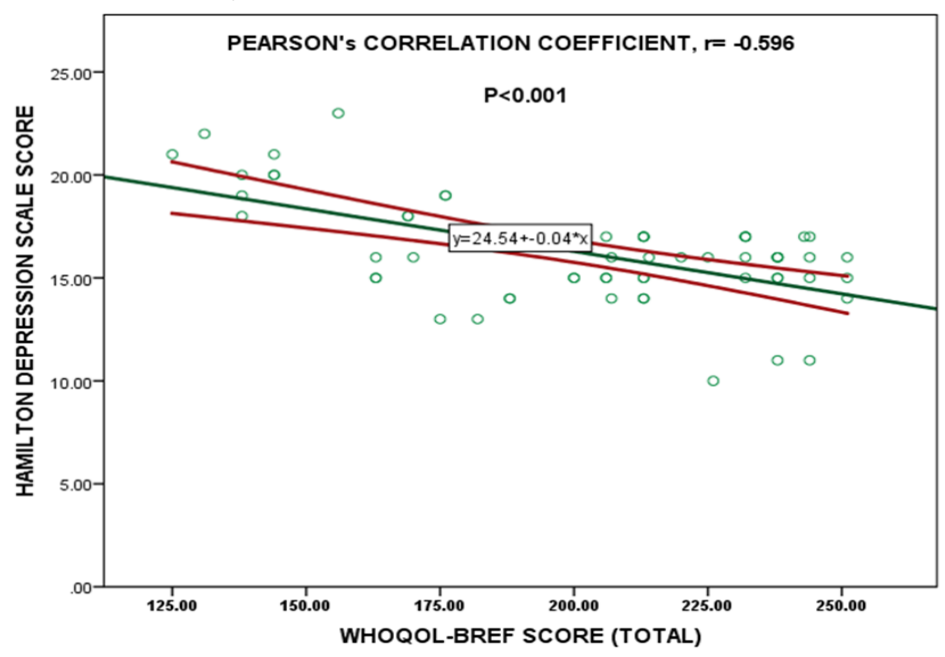


Table 3: Pearson's Correlation Analysis of HAM-D versus WHOQOL Scores

\begin{tabular}{|c|c|c|c|c|c|c|c|}
\hline & & HAMD & D1 & D2 & D3 & D4 & $T$ \\
\hline \multirow[t]{3}{*}{ HAMD } & Pearson Correlation & 1 & $-.467^{\star *}$ & $-.497^{\star *}$ & $-.398^{* *}$ & $-.378^{\star *}$ & $-.596^{\star *}$ \\
\hline & Sig. (2-tailed) & & .000 & .000 & .002 & .003 & .000 \\
\hline & $\mathrm{N}$ & 59 & 59 & 59 & 59 & 59 & 59 \\
\hline \multirow[t]{3}{*}{ D1 } & Pearson Correlation & $-.467^{* *}$ & 1 & $.325^{\star}$ & $.471^{* *}$ & $.368^{* *}$ & $.713^{* *}$ \\
\hline & Sig. (2-tailed) & .000 & & .012 & .000 & .004 & .000 \\
\hline & $\mathrm{N}$ & 59 & 59 & 59 & 59 & 59 & 59 \\
\hline \multirow[t]{3}{*}{ D2 } & Pearson Correlation & $-.497^{* *}$ & $.325^{\star}$ & 1 & $.423^{* *}$ & $.425^{* *}$ & $.754^{* \star}$ \\
\hline & Sig. (2-tailed) & .000 & .012 & & .001 & .001 & .000 \\
\hline & $\mathrm{N}$ & 59 & 59 & 59 & 59 & 59 & 59 \\
\hline \multirow[t]{3}{*}{ D3 } & Pearson Correlation & $-.398^{* *}$ & $.471^{* *}$ & $.423^{* *}$ & 1 & .193 & $.737^{\prime *}$ \\
\hline & Sig. (2-tailed) & .002 & .000 & .001 & & .142 & .000 \\
\hline & $\mathrm{N}$ & 59 & 59 & 59 & 59 & 59 & 59 \\
\hline \multirow[t]{3}{*}{ D4 } & Pearson Correlation & $-.378^{\star *}$ & $.368^{* *}$ & $.425^{* *}$ & .193 & 1 & $.692^{* *}$ \\
\hline & Sig. (2-tailed) & .003 & .004 & .001 & .142 & & .000 \\
\hline & $\mathrm{N}$ & 59 & 59 & 59 & 59 & 59 & 59 \\
\hline \multirow[t]{3}{*}{ T } & Pearson Correlation & $-.596^{* \star}$ & $.713^{* *}$ & $.754^{* *}$ & $.737^{* *}$ & $.692^{* *}$ & 1 \\
\hline & Sig. (2-tailed) & .000 & .000 & .000 & .000 & .000 & \\
\hline & $\mathrm{N}$ & 59 & 59 & 59 & 59 & 59 & 59 \\
\hline
\end{tabular}

\section{Discussion and Conclusion}

Gender is undoubtedly one of the major determinants of mental health of an individual. Consequently, men and women exhibit divergence in patterns of psychological distress and psychiatric problems. The underlying causality of this gender difference is not yet fully understood. One school of thought believes that hormonal influences related to the reproductive cycle of a woman may play a role increased/differential vulnerability to mental problems. Second, in the male dominated Indian society, females may be more prone to physical violence, sexual abuse, lack of emotional support and inability to make an earnings due to lack of education. Moreover, onset of menarche, maternity, and childbirth per se are stressful events in the life of a female ${ }^{(15)}$. The present cross section observational study analyzed depression and quality of life in females at different hormonal phases at a teaching, tertiary care hospital in northern part of the Indian subcontinent. The results of the present study revealed that the patterns of depression were different in each hormonal phase of the reproductive cycle. Patients from late perimenopausal group suffered with moderate followed by severe depression but the youngest suffered with moderate followed by mild depression. Daud and co-workers ${ }^{(16)}$ conducted a $^{2}$ descriptive study to find the prevalence of depression and explore its predictors and determinants among women in the reproductive age group (15 to 49 years) in Lahore, Pakistan. One hundred and eighty-six women of child bearing age were included in their study. Out of this sample size, 106 (57\%) women were nonpregnant/lactating and were less than 30 years of age. The authors found that 46(25\%) women in their study suffered from depression. The respondents were administered Beck's Depression Inventory and it was found that 41 (89\%) women were suffering from mild to moderate depression, while only 5 (11\%) had severe depression. Kanadys and co-workers ${ }^{(17)}$ conducted a study to assess the predictive factors of the quality of life of women in the peri-menopausal period. The study included 268 women in the peri-menopausal period. The participants were administered Women's Health Questionnaire - WHQ (a specific instrument used for investigating the quality of life of women at peri-menopausal age), Beck Depression Inventory (BDI) and an authorconstructed questionnaire. Regression analysis was done for estimation of the size of the 
explained variance and identification of predictor variables. The mean evaluations of the quality of life (WHQ) were lowest values (positive evaluation) for depressive symptoms, i.e. 0.26. In our study, a significant $(\mathrm{P}<0.001)$ inverse correlation was found between HAM-D scores and the overall quality of life (total WHOQOLBREF Score). Pearson's correlation coefficient, $r=$ -0.596. Depression scores also correlated significantly with all four domains of WHO quality of life.

Depression is a common condition in women and may be seen in all hormonal phases. Poor mental health may adversely affect women's family relations, social life, and their ability to function at school or work. It may adversely impact pregnancy, maternal infant bonding, maternal functioning, and infant and child health and development. In developed countries, depression may be associated with substance use and may put women at risk for future chronic disease, such as diabetes and heart disease. Therefore, early recognition of depression in women in reproductive age is important as depression may significantly impact health related quality of life.

Support and Grants: None

\section{References}

1. Patel V, Kirkwood B, Pednekar S, Pereira B, Barros P, Fernandes J, et al. Gender Disadvantage and Reproductive Health Risk Factors for Common Mental Disorders in Women. Archives of General Psychiatry. 2006 Apr;63(4):404-13.

2. Patton GC, Hibbert ME, Carlin J, Shao Q, Rosier M, Caust J, et al. Menarche and the onset of depression and anxiety in Victoria, Australia. J Epidemiol Community Health. 1996 Dec;50(6):661-6.

3. Capron C, The'rond C, Duyme M. Brief report: effect of menarcheal status and family structure on depressive symptoms and emotional/behavioural problems in young adolescent girls. J Adolesc. 2007 Feb;30(1):175-9.
4. Rierdan J, Koff E. Depressive symptomatology among very early maturing girls. J Youth Adolesc. 1991 Aug;20(4):415-25.

5. Ge X, Conger RD, Elder Jr GH. Coming of age too early: pubertal influences on girls' vulnerability to psychological distress. Child Dev. 1996 Dec;67(6):3386400.

6. Stice E, Presnell K, Bearman SK. Relation of early menarche to depression, eating disorders, substance abuse, and comorbid psychopathology among adolescent girls. Dev Psychol. 2001 Sep;37(5):608-19.

7. Chandran M, Tharyan P, Muliyil J, Abraham S. Post-partum depression in a cohort of women from a rural area of Tamil Nadu, India: Incidence and risk factors. $\quad \mathrm{Br} \quad \mathrm{J} \quad$ Psychiatry. 2002 Dec;181:499-504.

8. Sadock BJ, Sadock VA, Ruiz P. Neural Sciences. In: Pataki CS, Sussman N, editors. Synopsis of Psychiatry Behavioural Sciences/Clinical Psychiatry. 11th edition. New Delhi: Wolters Kluwer (India) Pvt Ltd; 2015. p. 65.

9. World Health Organization. Research on the Menopause in the 1990s (Report of a WHO Scientific Group), WHO Technical Report Series, 886. Geneva: World Health Organization; 1996.

10. Soules MR, Sherman S, Parrott E, Rebar R, Santoro N, Utian W, et al. Executive summary: Stages of Reproductive Aging Workshop (STRAW). Climacteric. 2001 Dec;4(4):267-72.

11. Soares CN. Depression in peri- and postmenopausal women: Prevalence, pathophysiology and pharmacological management. Drugs Aging. 2013 Sep;30(9):677-85.

12. Sengupta A. The emergence of the menopause in India. Climacteric. 2003 Jun;6(2):92-5. 
13. Hogan M. New freedom commission on mental health, achieving the promise: transforming mental health care in America. Psychiatr. Serv. 2003;54:14671474.

14. Shidhaye R, Patel V. Association of socioeconomic, gender and health factors with common mental disorders in women: a population-based study of 5703 married rural women in India. Int $\mathbf{J}$ Epidemiol. 2010 Dec;39(6):1510-21.

15. Dunkel Schetter C, Tanner L. Anxiety, depression, and stress in pregnancy: implications for mothers, children, research, and practice. Curr Opin Psychiatry 2012; 25:141-148.

16. Daud S, Kashif R, Anjum A. Prevalence, predictors, anddeterminants of depressionin women of reproductive age group. Biomedica 2008; 24:18-22.

17. Katarzyna Kanadys, Anna Wiktor-Stoma, Magdalena Lewicka, Magdalena Sulima, Henryk Wiktor. Predictors of the quality of life of women inperi-menopausal period. Annals of Agricultural and Environmental Medicine 2016;23(4): 641-648. 